\title{
Re-look at socioeconomic inequalities in stroke prevalence among urban Chinese: is the inflexion approaching?
}

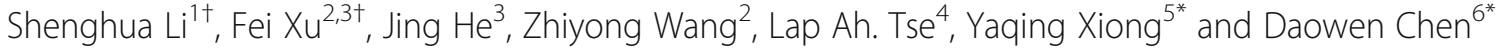

\begin{abstract}
Background: The present association between socioeconomic status (SES) and stroke is positive in developing communities, but it is negative in developed countries where a positive SES-stroke relationship was recorded several decades ago. We hypothesized that the SES-stroke relationship in developing societies mirrors the trajectory of the Western countries at some stage of economic development. This study aimed to examine whether this inflexion is approaching in China.
\end{abstract}

Methods: This study comprises of two cross-sectional surveys conducted in the same urban areas of Nanjing, China in 2000 (\$2000) and 2011 (S2011) using the same selection criteria (i.e., aged $\geq 35$ years) and sampling approach. Physician-diagnosed stroke was the outcome event, while family average income (FAI) was the explanatory variable and tertiled in our anlaysis. Mixed-effects models were used to examine the FAl-stroke association.

Results: Overall, 19,861 (response rate $=90.1 \%$ ) and 7824 (response rate $=82.8 \%$ ) participants participated in the S2000 and S2011, respectively. The prevalence of stroke increased by 2.5 -folds $(95 \% \mathrm{Cl}=2.2,2.9)$ from $2000(2.1 \%$, $95 \% \mathrm{Cl}=1.9 \%, 2.3 \%)$ to $2011(5.1 \%, 95 \% \mathrm{Cl}=4.6 \%, 5.6 \%)(p<0.01)$. Compared with the lower FAl category, the positive association between stroke prevalence and the higher FAl group decreased from $1.99(95 \% \mathrm{Cl}=1.55,2.56)$ in 2000 to $1.49(95 \% \mathrm{Cl}=1.09,2.03)$ in 2011 after control for potential confounders. A similar pattern was also observed for the middle FAl group $(1.60,95 \% \mathrm{Cl}=1.23,2.08$ in 2000 vs. 1.37, 95\%Cl=1.01, 1.88 in 2011).

Conclusions: This study revealed that socioeconomic inequalities in stroke were diminishing in regional China during the recent 11-year period, although the SES-stroke association was still positive. Tailored intervention against stroke should currently target on SES-vulnerable people.

Keywords: Stroke, Prevalence, Socioeconomic status, Family average income

\section{Background}

Inconsistent association between socioeconomic status (SES) and stroke prevalence has been reported worldwide, with various indicators of SEE in different studies [1-10]. Inflexional results were observed at different socioeconomic stages in Western countries, transiting from a positive association decades ago to a negative link in more recent years [1-10].

\footnotetext{
*Correspondence: xiongyaqingnj@126.com; chendaowen@126.com ${ }^{\dagger}$ Equal contributors

${ }^{5}$ Jiangsu Province Geriatric Hospital, 30, Luojia Road, Nanjing 210024, China ${ }^{6}$ Department of Neurology, The Affiliated Brain Hospital of Nanjing Medical University, 264, Guangzhou Road, Nanjing 210029, China

Full list of author information is available at the end of the article
}

SES is a complex index and is commonly measured by residents' income, educational attainment or occupation. Although different SES measures can provide different information on residents' socioeconomic positions within their communities [11], family average income (FAI) has been shown to be a more sensitive indicator of SES as it can more realistically reflect material measures than educational attainment or occupation [12-14].

In China, it has been documented that the prevalence of stroke was positively associated with increasing levels of all SES indices, including family average income, educational attainment and occupation [6]. As China has experienced rapid economic development since the "Open Door" policy launched in 1978, the Gross 
Domestic Product (GDP) in 2015 is approximately 185.4 times high as that in 1978 based on the statistics of China currency [15]. We hypothesized that the relationship between SES and stroke in China mirrors the trajectory of that in the Western countries, with approximately 30 years lag as a result of economic growth and social development.

We adopted FAI as an indicator of SES in this study, aiming at examining whether there was an inflexion of the association between SES and stroke (i.e., transiting from a positive association to a negative one) by comparing representative data from surveys in 2000 and 2011 among Chinese adults in urban areas of China.

\section{Methods}

\section{Participants and sampling}

Two population-based cross-sectional surveys were conducted separately in 2000 and 2011 (hereafter, S2000 and S2011) in Nanjing, China. Nanjing is located in the east of China with a registered population of 5.6 million in 2000 and 6.4 million in 2011. Participants of these two surveys were randomly selected from the same urban areas of Nanjing. In China, the administrative system comprises of five strata: Central government, Provincial/Municipal government, District/County government, Street/Town Government and Administrative Village.

The same sampling approaches were adopted for the two surveys. First, targeted urban districts were randomly selected. Then, administrative streets were chosen from the selected districts. Next, administrative villages were selected from those chosen streets. Lastly, neighbourhoods were randomly selected from the selected administrative villages and all the eligible participants from those neighbourhoods were invited to take part in the survey. To be eligible, participants had to be local residents registered in the chosen neighbourhoods for at least 5 years and aged 35 years or above. Overall, these two surveys used the same inclusion criteria to recruit study participants.

Ethics approval was obtained separately for each survey from the Academic and Ethical Committee of Nanjing Municipal Center for Disease Control and Prevention. Informed consent was obtained from each participant prior to each survey.

\section{Sample size estimation}

The prevalence of stroke used to estimate the sample size of our S2000 was $1.9 \%$ according to a populationbased survey in urban areas of a neighbour city in 2000 [16]. Given this reference stroke prevalence of $1.9 \%$ in 2000 and assuming an absolute precision of $0.2 \%$, the sample size of S2000 was estimated to be approximately 17,901 . On the other hand, it was reported that the prevalence of stroke was 3.6\% among a representative sample of local urban adults in 2007 [17]. Assuming an absolute precision of $0.4 \%$ and stroke prevalence of $3.6 \%$, the required sample size for S2011 was calculated to be about 6987.

These statistics suggested that statistical power was adequate for achieving the research objectives of the current study. The actual number of participants for S2000 and S2011 were more than the required sample size which indicates that the statistical power for the two surveys was adequate for achieving the research objectives of our current study.

\section{Data collection and questionnaires}

A standardized questionnaire was applied in the S2000 survey [18] to collect information on participants' sociodemographic characteristics, stroke status, blood pressure status, diabetes status, number of family members, total monthly income of family, smoking status, alcohol drinking, and physical activity (PA), consumption of red-meat and healthcare payment. The same questionnaire was also used for the S2011 survey except for physical activity. In S2111, the validated Chinese version of International Physical Activity Questionnaire (IPAQ-CHIN) was used to collect information on PA [19]. In each survey, questionnaire was administered by well-trained interviewers.

\section{Specification of study variables \\ Outcome variable-stroke prevalence}

Self-reported stroke was treated as outcome variable and categorized into: (1)"stroke" or (2)"non-stroke" in this study. Stroke was diagnosed based on the WHO MONICA criteria [20]. Each participant was invited to respond to the question "Have you ever been diagnosed as a stroke patient by a doctor or doctors at a hospital?" via face-to-face interview. If the answer was "Yes", the participant/guardian was then asked to show the patient's medical record to confirm his/her declaration. In China, each resident has a personal medical record with him-/her-self after he/she visits a doctor. Details about sub-types of stroke, date of diagnosis, evidence related to the diagnosis, hospital of diagnosis and the current medication status (if any) were extracted from the medical record. No medical record was traced if the participant answered "No" to the question about stroke. It was less likely that the participant forget/ignore experiencing a stroke event diagnosed by clinical doctors.

\section{Explanatory variable-family average income}

Family average income was used as the explanatory variable to indicate participant's socio-economic status in this study. FAI was defined as the self-reported total monthly incomes of all family members divided by the total number of family members (including children and 
elderly), which was further tertiled as lower, middle and higher sub-group for analysis. FAI, as an individual level marker of SES, has been examined to be able to more sensitively and realistically reflect participants' socioeconomic standing in the community than other indicators such as education or occupation [12-14], therefore FAI was chosen as the indicator of SES in this study. Family members referred to those who lived together and shared living-related expenditures. The total monthly income of all family members was the total monthly earnings of the whole family, including salaries, pensions and allowances, and money from selling goods and products.

\section{Potential confounding factors}

In our analysis, the available conventional stroke risk factors were treated as potential confounding factors, including age, gender, educational attainment, occupation, smoking, alcohol drinking, red-meat consumption, healthcare payment, diabetic status, blood pressure status, body weight status and leisure-time physical activity (LTPA). Socio-demographic covariates were categorized into: (1) younger (35-49 years), middle (50-64 years) or older (65+ years) for age; (2) men and women for gender; (3) 0-6 years, 7-12 years, or 13+ years based on years of schooling completed by participants for educational attainment; and (4) white collar and blue collar according to their workplaces (at office or not) for occupation.

Smoking status was classified as 'smokers' (those who smoked at least one cigarette per day continuously for at least one year, or smoked at least eighteen packs in total each year) and 'non-smokers' (those who had never smoked cigarettes, or smoked but did not meet the criteria of 'smokers'), while alcohol drinking status was categorized into "drinkers" (those who drank alcohol two or more times per week on average, for at least 1 year) and "non- drinkers" (those who never drank or drank alcohol but did not meet the criterion of regular drinkers).

Red-meat consumption was tertiled as lower, middle and upper group based on the distribution of weekly frequency of consumption [21]. The information on weekly consumption of red meat was gathered using a validated food frequency questionnaire [22]. Healthcare payment was categorized as "Insured" (by employers) and "Noninsured" (healthcare paid by selves). Healthcare payment referred to how the healthcare fees were paid. Diabetic status was grouped as "Yes" or "No" according to the diagnostic information from the personal medical record. The status of blood pressure was categorized as "Hypertension" and "Non-hypertension". Hypertension was diagnosed for a participant by registered physicians if either the systolic blood pressure exceeded $140 \mathrm{mmHg}$ or the diastolic blood pressure exceeded $90 \mathrm{mmHg}$, or both, with consideration of clinical symptoms. Moreover, those participants who have prescribed to take antihypertension medications were also defined as hypertensive patients even if their blood pressure was normal when measured.

Body weight status was classified as "Normal weight" and "Excess weight" based on the recommended cutoffs of body mass index (BMI) [weight $(\mathrm{kg}) /$ height $\left(\mathrm{m}^{2}\right)$ ] for Chinese adults. Excess weight was defined as BMI equal to or greater than 24 , while non-excess weight as BMI less than 24. [23] Height and weight were objectively measured twice at each visit and the mean of the two readings was used in the analysis.

Leisure-time physical activity was classified as "Sufficient (the sum of moderate-intensity and doubled vigorous-intensity PA time $\geq 150$ minutes/week)" and "Insufficient (those not meet the above mentioned criteria of "Sufficient" PA)" according to existing recommendations [24]. The information on LTPA (type of intensity, weekly frequency and duration of each PA session) in the past week was collected from each participant, although different instruments were used in the two surveys. In S2000, LTPA was assessed with a widelyaccepted questionnaire in which two likert items were used. The first item was "In last week, what type of LTPA you engaged in (No LTPA, Light, Moderate or Vigorous intensity)?". The answer was "No" if the participant did not engage in LTPA in last week. If the answer was either light, moderate or vigorous intensity, the next question was "How many times you engaged in such LTPA separately (at least $15 \mathrm{~min}$ for each session) in last week (once, 2, 3, or 5 times per week)?". For the S2011, LTPA was measured using the validated Chinese short-version of the International Physical Activity Questionnaire (IPAQ-CHN) [19].

\section{Data analysis}

Chi-square test was calculated to compare the categorical socio-demographic characteristics of participants. Mixed-effects models were performed separately to compute the odds ratios (ORs) and 95\% confidence intervals $(95 \% \mathrm{CI})$ for the relationship between FAI and stroke based on two models. Model 1 was a univariate analysis with only FAI as the single predictor; Model 2 was a multivariate analysis with adjustment for conventional risk factors of stroke, including age, gender, educational attainment, occupation, smoking, alcohol drinking, red-meat consumption frequency, healthcare insurance, diabetes, status of blood pressure, body weight status, leisure-time physical activity and survey area (potential clustering by administrative unit). $p<0.05$ was used to assess the two-side statistical significance. Data analyses were conducted using SPSS 21.0 (IBM Corp, Armonk, NY, USA). 


\section{Results}

\section{Socio-demographic characteristics}

There were 19,861 (response rate $=90.1 \%$ ) and 7824 (response rate $=82.8 \%$ ) adults completing the S2000 and S2011 survey, respectively. Table 1 displays the selected socio-demographic characteristics in both surveys. Compared with the S2000, participants in the S2011 were significantly elder and less educated, but more whitecollar workers and insured healthcare $(71.9 \%$ in 2000 vs. $75.3 \%$ in 2011). Mean value of FAI was significantly increased by 2.9 times from 2000 to 2011 among our survey participants $(p<0.001)$. There was no significant difference in socio-demographic characteristics between respondents and non-respondents in each survey.

There were $44.3 \%$ vs. $40.3 \%, 34.5 \%$ vs. $34.0 \%$ and $21.2 \%$ vs. $25.7 \%$ of participants within each age-group (35-49, $50-64$ and $65+)$ for S2000 vs. S2011 $(p<0.05)$. This was in line with the local census data that the proportion of residents aged $65+$ years old within general population significantly increased from $16.5 \%$ in 2000 to $17.7 \%$ in $2011(p<0.05)$. The male to female ratio in S2000 (1:1.01) and S2011 (1:1.02) was comparable to that of the census data for the corresponding year $(p>0.05)$.

Table 1 Selected socio-demographic characteristics of participants in survey 2000 and 2011 in Nanjing, China

\begin{tabular}{|c|c|c|c|}
\hline \multirow[t]{2}{*}{ Variables } & $\begin{array}{l}\text { Survey } 2000 \\
(N=19,861)\end{array}$ & $\begin{array}{l}\text { Survey } 2011 \\
(N=7824)\end{array}$ & \multirow[t]{2}{*}{$p$ value $^{b}$} \\
\hline & $\%(n)$ & \multirow{2}{*}{\multicolumn{2}{|c|}{$\%(n)$}} \\
\hline \multicolumn{2}{|l|}{ Age (yrs) } & & \\
\hline $35-49$ & $44.3(8793)$ & $40.3(3154)$ & \multirow[t]{3}{*}{$<0.01$} \\
\hline $50-64$ & $34.5(6849)$ & $34.0(2662)$ & \\
\hline $65+$ & $21.2(4219)$ & $25.7(2008)$ & \\
\hline \multicolumn{4}{|l|}{ Gender } \\
\hline Female & $50.3(9990)$ & $49.4(3867)$ & \multirow[t]{2}{*}{0.68} \\
\hline Male & $49.7(9871)$ & $50.6(3957)$ & \\
\hline \multicolumn{4}{|c|}{ Educational attainment (yrs) } \\
\hline $0-9$ & $54.6(10849)$ & $59.8(4681)$ & \multirow[t]{3}{*}{$<0.01$} \\
\hline $10-12$ & $25.2(4996)$ & $24.6(1928)$ & \\
\hline $13+$ & $20.2(4016)$ & $15.5(1215)$ & \\
\hline \multicolumn{4}{|l|}{ Occupation $^{a}$} \\
\hline Blue collar & $51.2(10178)$ & 49.7 (3889) & \multirow[t]{2}{*}{0.01} \\
\hline White collar & $48.8(9683)$ & $50.3(3935)$ & \\
\hline \multicolumn{4}{|c|}{ Healthcare insurance } \\
\hline Insured & $71.9(14282)$ & $75.3(5894)$ & \multirow[t]{2}{*}{$<0.01$} \\
\hline Non-insured & $28.1(5579)$ & $24.7(1930)$ & \\
\hline $\mathrm{FAl}(¥ / \mathrm{m})$ & $551.3 \pm 426.7$ & $1575.6 \pm 1243.2$ & $<0.001$ \\
\hline
\end{tabular}

${ }^{\mathrm{a} B l u e}$ collar = farmer, factory worker, forestry worker, fisher and military person salespeople, house worker and vehicle driver; White collar = office worker, teacher, doctor and academic researcher, government officer

${ }^{b} \mathrm{Chi}$-square test was calculated to compare the categorical socio-demographic characteristics of participants

\section{Prevalence of self-reported stroke}

Table 2 shows the prevalence of self-reported stroke among participants in S2000 and S2011, respectively. The prevalence of self-reported stroke was $2.1 \%$ (95\% CI $=1.9 \%, 2.3 \%)$ in 2000 , while it increased to $5.1 \%$ (95\%CI $=4.6 \%, 5.6 \%)$ in 2011 with an increasing rate of 2.5 -folds $(95 \% \mathrm{CI}=2.2,2.9) \quad(p<0.01)$. Although the prevalence of stroke was the smallest amongst the five major defined chronic diseases $(0.1 \%$ in 2000 and $0.7 \%$ in 2011), the speed of increase was the fastest among younger age-group ( 4.5 times $[95 \% \mathrm{CI}=2.3,9.0]$ increase) compared to the middle-aged $(2.6$ times $[95 \% \mathrm{CI}=2.0,3.4])$ or older $(2.1$ times $[95 \% \mathrm{CI}=1.7,2.5])$ group of participants $(p=0.04)$. From 2000 to 2011 , there were 2.4 [95\% CI = $2.0,2.9]$ and $2.6[95 \% \mathrm{CI}=2.1,3.2]$ times increase in stroke prevalence among men and women $(p=0.66)$, and it increased $2.5[95 \% \mathrm{CI}=2.2,2.9]$ and $2.2[95 \% \mathrm{CI}=$ $1.6,3.2]$ times among those with and without insured healthcare, respectively, $(p=0.51)$.

\section{Relationship between FAI and stroke}

Table 3 presents the relationship between FAI and stroke in S2000 and S2011, separately. Compared with the

Table 2 Prevalence of self-reported stroke by age and gender among urban residents in 2000 and 2011 in Nanjing, China

\begin{tabular}{lll}
\hline Variables & \multicolumn{2}{l}{ Prevalence of self-reported stroke $(\%, \mathrm{n})$} \\
\cline { 2 - 3 } & Survey $2000(\mathrm{~N}=19,861)$ & Survey $2011(\mathrm{~N}=7824)$ \\
\hline Overall & $2.1(416)$ & $5.1(400)$ \\
Age (yrs) & & $0.7(21)$ \\
$35-49$ & $0.1(13)$ & $4.7(124)$ \\
$50-64$ & $1.8(125)$ & $12.7(255)$ \\
$65+$ & $6.6(278)$ & $4.3(168)$ \\
Gender & & $5.9(232)$ \\
Women & $1.7(171)$ & $5.7(267)$ \\
Men & $2.5(245)$ & $4.2(81)$ \\
Education (yrs) & & $4.3(52)$ \\
0-9 & $2.1(232)$ & \\
10-12 & $1.4(70)$ & $2.3(88)$ \\
13+ & $2.8(114)$ & $7.9(312)$ \\
Occupationt & & $2.9(56)$ \\
Blue collar & $0.9(91)$ & \\
White collar & $3.4(325)$ & \\
Healthcare payment & $2.4(342)$ & \\
Insured & $1.3(74)$ & \\
Non-insured & & \\
\hline
\end{tabular}

†Blue collar = farmer, factory worker, forestry worker, fisher and military person, salespeople, house worker and vehicle driver; White collar = office worker, teacher, doctor and academic researcher, government officer 
Table 3 The relationship between family average income and self-reported stroke prevalence in 2000 and 2011 among urban residents in Nanjing, China

\begin{tabular}{|c|c|c|c|c|c|c|c|c|c|}
\hline \multirow[b]{2}{*}{ Variables } & \multirow[b]{2}{*}{$\begin{array}{l}\text { FAl } \\
\text { Category }\end{array}$} & \multicolumn{3}{|c|}{ The S2000 study } & \multicolumn{3}{|c|}{ The S2011 study } & \multirow{2}{*}{$\begin{array}{l}\text { P value for comparison } \\
\text { of ORs between S2000 } \\
\text { and S2011 }\end{array}$} & \multirow{2}{*}{$\begin{array}{l}\text { P value for comparison } \\
\text { of Adjusted ORs between } \\
\text { S2000 and S2011 }\end{array}$} \\
\hline & & $\begin{array}{l}\text { Stroke } \\
(\% \text { and } n)\end{array}$ & $\begin{array}{l}\text { Unadjusted } \\
\text { Odds ratio } \\
(95 \% \mathrm{Cl}) \\
\end{array}$ & $\begin{array}{l}\text { Adjusted } \\
\text { Odds ratio a } \\
(95 \% \mathrm{Cl}) \\
\end{array}$ & $\begin{array}{l}\text { Stroke } \\
(\% \text { and } n)\end{array}$ & $\begin{array}{l}\text { Unadjusted } \\
\text { Odds ratio } \\
(95 \% \mathrm{Cl})\end{array}$ & $\begin{array}{l}\text { Adjusted } \\
\text { Odds ratio } \\
(95 \% \mathrm{Cl}) \\
\end{array}$ & & \\
\hline \multicolumn{10}{|l|}{ Overall } \\
\hline & Lower & $1.1(79)$ & 1 & 1 & $3.5(103)$ & & 1 & 0.022 & 0.031 \\
\hline & Middle & $2.3(144)$ & $\begin{array}{l}2.06 \\
(1.57,2.72)\end{array}$ & $\begin{array}{l}1.46 \\
(1.07,1.97)\end{array}$ & $5.5(130)$ & $\begin{array}{l}1.60 \\
(1.23,2.08)\end{array}$ & $\begin{array}{l}1.37 \\
(1.01,1.88)\end{array}$ & & \\
\hline & Higher & $2.9(193)$ & $\begin{array}{l}2.65 \\
(2.04,3.45)\end{array}$ & $\begin{array}{l}1.66 \\
(1.19,2.32)\end{array}$ & $6.7(167)$ & $\begin{array}{l}1.99 \\
(1.55,2.56)\end{array}$ & $\begin{array}{l}1.49 \\
(1.09,2.03)\end{array}$ & & \\
\hline \multicolumn{10}{|l|}{ Age (yrs) } \\
\hline \multicolumn{10}{|l|}{$35-49$} \\
\hline & Lower & $0.3(10)$ & 1 & 1 & $0.6(8)$ & & 1 & 0.580 & 0.448 \\
\hline & Middle & $0.1(3)$ & $\begin{array}{l}0.41 \\
(0.11,1.50)\end{array}$ & $\begin{array}{l}0.34 \\
(0.09,1.36)\end{array}$ & $0.6(5)$ & $\begin{array}{l}1.02 \\
(0.33,3.14)\end{array}$ & $\begin{array}{l}1.33 \\
(0.41,4.34)\end{array}$ & & \\
\hline & Higher & $0.0(0)$ & 0 & 0 & $0.9(8)$ & $\begin{array}{l}1.59 \\
(0.60,4.25)\end{array}$ & $\begin{array}{l}2.17 \\
(0.69,6.81)\end{array}$ & & \\
\hline \multicolumn{10}{|l|}{$50-64$} \\
\hline & Lower & $1.2(23)$ & 1 & 1 & $3.7(31)$ & & 1 & 0.041 & 0.043 \\
\hline & Middle & $2.2(50)$ & $\begin{array}{l}1.87 \\
(1.14,3.07)\end{array}$ & $\begin{array}{l}1.51 \\
(0.89,2.56)\end{array}$ & $5.0(48)$ & $\begin{array}{l}1.37 \\
(0.87,2.18)\end{array}$ & $\begin{array}{l}1.18 \\
(0.69,2.01)\end{array}$ & & \\
\hline & Higher & $2.0(52)$ & $\begin{array}{l}1.69 \\
(1.03,2.78)\end{array}$ & $\begin{array}{l}1.41 \\
(0.79,2.52)\end{array}$ & $5.3(45)$ & $\begin{array}{l}1.46 \\
(0.91,2.33)\end{array}$ & $\begin{array}{l}1.16 \\
(0.66,2.03)\end{array}$ & & \\
\hline \multicolumn{10}{|l|}{$65+$} \\
\hline & Lower & $3.3(46)$ & 1 & 1 & $9.1(64)$ & & 1 & 0.004 & 0.013 \\
\hline & Middle & $6.9(91)$ & $\begin{array}{l}2.19 \\
(1.52,3.15)\end{array}$ & $\begin{array}{l}1.69 \\
(1.13,2.52)\end{array}$ & $13.8(77)$ & $\begin{array}{l}1.60 \\
(1.13,2.28)\end{array}$ & $\begin{array}{l}1.50 \\
(0.99,2.29)\end{array}$ & & \\
\hline & Higher & $9.4(141)$ & $\begin{array}{l}3.05 \\
(2.17,4.28)\end{array}$ & $\begin{array}{l}2.21 \\
(1.43,3.42)\end{array}$ & $15.2(114)$ & $\begin{array}{l}1.80 \\
(1.30,2.49)\end{array}$ & $\begin{array}{l}1.58 \\
(1.06,2.35)\end{array}$ & & \\
\hline \multicolumn{10}{|l|}{ Gender } \\
\hline \multicolumn{10}{|c|}{ Women } \\
\hline & Lower & $0.9(32)$ & 1 & 1 & $3.1(45)$ & & 1 & 0.014 & 0.011 \\
\hline & Middle & $1.9(58)$ & $\begin{array}{l}2.15 \\
(1.39,3.32)\end{array}$ & $\begin{array}{l}1.88 \\
(1.17,3.03)\end{array}$ & $4.1(52)$ & $\begin{array}{l}1.33 \\
(0.89,2.00)\end{array}$ & $\begin{array}{l}1.39 \\
(0.85,2.26)\end{array}$ & & \\
\hline & Higher & $2.5(81)$ & $\begin{array}{l}2.88 \\
(1.91,4.35)\end{array}$ & $\begin{array}{l}2.21 \\
(1.30,3.74)\end{array}$ & $6.1(71)$ & $\begin{array}{l}2.02 \\
(1.38,2.96)\end{array}$ & $\begin{array}{l}1.74 \\
(1.06,2.84)\end{array}$ & & \\
\hline \multicolumn{10}{|l|}{ Men } \\
\hline & Lower & $1.4(47)$ & 1 & 1 & $3.8(58)$ & & 1 & 0.032 & 0.052 \\
\hline & Middle & $2.7(86)$ & $\begin{array}{l}1.97 \\
(1.38,2.82)\end{array}$ & $\begin{array}{l}1.21 \\
(0.82,1.81)\end{array}$ & $7.0(78)$ & $\begin{array}{l}1.88 \\
(1.33,2.67)\end{array}$ & $\begin{array}{l}1.33 \\
(0.88,2.00)\end{array}$ & & \\
\hline & Higher & $3.4(112)$ & $\begin{array}{l}2.46 \\
(1.74,3.47)\end{array}$ & $\begin{array}{l}1.36 \\
(0.88,2.11)\end{array}$ & $7.2(96)$ & $\begin{array}{l}1.95 \\
(1.40,2.73)\end{array}$ & $\begin{array}{l}1.23 \\
(0.82,1.85)\end{array}$ & & \\
\hline
\end{tabular}

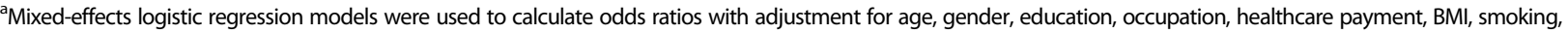
alcohol drinking, red-meat consumption, diabetes, high blood pressure, leisure-time physical activity and survey area (potential clustering effects at survey area level)

b Logistic regression models were used to make comparison of ORs between the two studies, with stroke as the outcome variable, FAl, survey (S2000/S2011) and the FAl-bysurvey interaction term as the explanatory variables. For the comparison of Adjusted ORs between tow studies, all related potential confounders were controlled in analysis

lower FAI category, the positive association of stroke prevalence with the high and middle FAI group decreased from $1.99(95 \% \mathrm{CI}=1.55,2.56)$ and $1.60(95 \% \mathrm{CI}$
$=1.23,2.08)$ in $\mathrm{S} 2000$ to $1.49(95 \% \mathrm{CI}=1.09,2.03)$ and $1.37(95 \% \mathrm{CI}=1.01,1.88)$ in 2011 , after control for potential confounders. Interestingly, with consideration of 
potential confounders, the size of the disparities of stroke prevalence within FAI categories attenuated significantly among overall participants $(p=0.03)$ over the 11 years. Furthermore, after stratified analysis, such significant attenuations were observed in women $(p=0.01)$ and among those middle-aged $(p=0.04)$ and elders aged $65+$ years old $(\mathrm{p}=0.01)$.

\section{Discussion}

This study demonstrated a 2.4 times increase in the prevalence of self-reported stroke among urban Chinese adults aged 35 years old or above from 2000 to 2011 . Inequalities in SES and stroke prevalence among urban Chinese had attenuated significantly over the 11-year period, despite the association between FAI (a more sensitive indicator of SES) and stroke was still positive. These findings suggested that the SES-stroke patterns in China nowadays were still similar to those in the Western countries approximately 30 years ago (positive association) [1-10] but the strength of such a positive association has been significantly weakening, which might imply that an inflexion of direction of SES-stroke relationship may be approaching in urban Chinese as a consequence of continuing economic growth and social development.

SES can not only simply predict participants' social standing but also exert an important influence on experience of stroke. Currently, the patterns of relationship between SES and stroke were different in societies with different economic and social development stages - being negative in developed societies but positive in developing communities [25]. Given that the economic and social development goes on in China and the direction of association between SES and stroke has been changed from being positive at earlier development stage several decades ago to being negative at the present developed stage in developed countries, it is expected that such a pattern in China may gradually transit from being positive to negative in th future.

Regardless of the direction of its association with stroke, SES is a valuable determinant of stroke at population level worldwide. It is possible to optimize the performance-investment ratio for stroke prevention programs only if those people with vulnerable SES are identified and can receive more precise prevention approaches as early as possible. Therefore, it is of realistic meaningfulness for population-based stroke precise prevention to continuously examine the relationship between SES and stroke at different economic development stages for different communities. This is of particular importance for developing countries, as their economy is less developed and the subsequent transitions may involve in changing in both socioeconomic and lifestyle related factors.
Although it is not well understood how the specific SES can influence stroke, there are several potential mechanisms attributable to inequalities in socioeconomic determinants to health. These can be explained by people with different SES may have different lifestyles, behavioural patterns, psychosocial stress, access to healthcare and material circumstances $[1,5,26,27]$. Among those potential determinants, psychosocial factors and healthcare access could explain only a very small portion of SES difference in stroke prevalence, while conventional lifestyle and behavioural risk factors were the main driven power for the disparities of stroke prevalence in people with different SES $[7,20]$. Dietary and physical activity patterns and anthropometric scenarios vary among people with the same SES in developed and developing communities. It is well known that SES was negatively associated with the consumption of high-dense energy food, insufficient PA and being obese in developed countries $[28,29]$, while the scenarios were completely inverse in developing communities [30, 31]. This means that residents within lower SES stratum were less likely to consume high-dense energy foods and to be obese, but more likely to engage in sufficient PA than those with higher SES in developing societies, as is the case in the current context of China. Such disparities in the distribution of conventional risk factors in developed and developing communities might, at least partially, act as intermediates for the influence of SES on the development of stroke.

China has been experiencing a rapid economic growth over the past decades [15] and certainly has been seeing a continuous change in lifestyle and behavior patterns. Chinese people tended to consuming more high-dense energy foods and doing less physical activity than those were done decades ago $[32,33]$, which suggested that lifestyle and behavioral patterns have been Westernizing in China. Therefore, it is foreseeable that the direction of association between SES and stroke in China is prone to being similar to that in the Western countries. It is of interest to know at what stage of economic development that the direction of FAI-stroke association will change in China and when the critical time of the diminishing disparity between FAI and stroke comes before the presence of a negative relationship. This is of particular public health importance for developing population-level stroke prevention programs in China, as the SES-related vulnerable sub-population for stroke will be different at different economic development stage in a society.

There are several strengths of this study. First, representative participants were randomly selected for each survey from the same urban areas of Nanjing. Second, sufficient cases of outcome event were guaranteed by large sample size of each survey. Third, the two surveys were led by the same principle investigator, which 
implied that the study qualities would be under control for each survey. Fourth, the same instrument was used in the two surveys. Fifth, FAI, a sensitive SES indicator, was used to represent SES. Finally, conventional confounders were sufficiently considered in our analysis.

This study also has several limitations. (1) The outcome event was the diagnosed stroke, which may cause stroke prevalence under-estimated, although strong agreement has been documented between self-reported stroke cases and those were confirmed by medical record review or CT scan [34, 35]. (2) Family incomes were also self-reported. This may result in potentially under-estimating incomes, as Chinese people tend to under-report their earnings [36]; however, such misclassification on FAI is likely non-differential, which would lead the effect size to be under-estimated. (3) The cross-sectional design of these two surveys did not allow us inferring causality for the SES and stroke in this study. However, this study also disclosed relations between socioeconomic determinants and stroke prevalence which provides important message for policy prevention and medical resources' allocation for the existing cases. (4) We measured the SES-stroke association at individual level without including a macro-level of social determinants such as policy; however, policy implementation within a same urban area was similar and thus it was not a major concern. (5) The influence of inflation on FAI was not considered (Consumer Price Index in 2011 was 1.28 times that in 2000 in Nanjing) [37], which might affect the comparability of FAI overtime, but this was not be a major concern as we only compared the contemporized pattern of FAI with stroke.

\section{Conclusions}

Socioeconomic inequalities in stroke prevalence among urban Chinese were diminishing, despite the association between SES and stroke was still positive. This inflexion tendency was prominent in women and those people aged 50+ years old. Presently, policy and individual intervention tackling socioeconomic inequalities should target on the low income families who have increased stroke prevalence. Further reduction of socioeconomic inequalities in stroke prevalence among all Chinese is a national goal for the improvement of public health.

\section{Abbreviations \\ BMI: Body mass index; Cl: Confidence intervals; FAl: Family average income; GDP: Gross Domestic Product; IPAQ: International Physical Activity Questionnaire; IPAQ-CHN: Chinese version of the International Physical Activity Questionnaire; LTPA: Leisure-time physical activity; ORs: Odds ratios; PA: Physical activity; SES: Socioeconomic status; WHO: World Health organization}

\section{Acknowledgements}

We are grateful to those workers who were involved in data collection and Dr. Qing Ye for his assistance in data management and analysis.

\section{Funding}

The work was supported by Nanjing Municipal Science and Technology Development Foundation (201503054). This funding body specifically supported the study design, data collection and analysis, as well as manuscript preparation.

Availability of data and materials

It is confirmed that the related data and material will be available upon request to either of the two corresponding authors.

\section{Authors' contributions}

Conceived and designed the study: FX, LAT, YX and DC. Data collection: FX, $J H$ and ZW. Analyzed the data: FX and JH. Wrote the paper: SL, FX, JH, ZW, LAT, YX and DC. Critical revision of the manuscript: SL, FX, JH, ZW, LAT, YX and DC. Supervised the study: FX, LAT, YX and DC. All authors read and approved the final manuscript.

\section{Ethics approval and consent to participate}

Written informed consent was obtained from each participant prior to each survey. This study was approved by the Academic and Ethical Committee of Nanjing Municipal Center for Disease Control and Prevention.

Consent for publication

Not applicable.

\section{Competing interests}

The authors have declared that no competing interests exist.

\section{Publisher's Note}

Springer Nature remains neutral with regard to jurisdictional claims in published maps and institutional affiliations.

\section{Author details \\ ${ }^{1}$ Department of Neurology, The Affiliated Jiangning Hospital of Nanjing Medical University, Nanjing, China. ${ }^{2}$ Nanjing Municipal Center for Disease Control and Prevention, Nanjing, China. ${ }^{3}$ Department of Epidemiology, School of Public Health, Nanjing Medical University, Nanjing, China. ${ }^{4}$ School of Public Health and Primary Care, The Chinese University of Hong Kong, Hong Kong, China. ${ }^{5}$ Jiangsu Province Geriatric Hospital, 30, Luojia Road, Nanjing 210024, China. ${ }^{6}$ Department of Neurology, The Affiliated Brain Hospital of Nanjing Medical University, 264, Guangzhou Road, Nanjing 210029, China.}

Received: 5 August 2017 Accepted: 8 March 2018

Published online: 20 March 2018

\section{References}

1. Cox AM, McKevitt C, Rudd AG, Wolfe CD. Socioeconomic status and stroke. Lancet Neurol. 2006;5:181-8.

2. Hart $\mathrm{CL}$, Hole DJ, Smith GD. Influence of socioeconomic circumstances in early and later life on stroke risk among men in a Scottish cohort study. Stroke. 2000;31:2093-7.

3. Kleindorfer DO, Lindsell C, Broderick J, Flaherty ML, Woo D, Alwell K, Moomaw CJ, Ewing I, Schneider A, Kissela BM. Impact of socioeconomic status on stroke incidence: a population-based study. Ann Neurol. 2006;60:480-4.

4. Thrift AG, Dewey HM, Sturm JW, Paul SL, Gilligan AK, Srikanth VK, Macdonell RA, McNeil JJ, Macleod MR, Donnan GA. Greater incidence of both fatal and nonfatal strokes in disadvantaged areas: the Northeast Melbourne stroke incidence study. Stroke. 2006:37:877-82

5. Avendano M, Kawachi I, Van Lenthe F, Boshuizen HC, Mackenbach JP, Van den Bos GA, Fay ME, Berkman LF. Socioeconomic status and stroke incidence in the US elderly: the role of risk factors in the EPESE study. Stroke. 2006;37:1368-73.

6. Xu F, Tse LA, Yin XM, Yu IT, Griffiths S. Impact of socio-economic factors on stroke prevalence among urban and rural residents in mainland China. BMC Public Health. 2008:8:170

7. Hart $\mathrm{CL}$, Hole DJ, Smith GD. The contribution of risk factors to stroke differentials, by socioeconomic position in adulthood: the Renfrew/ paisley study. Am J Public Health. 2000;90:1788-91.

8. Morris RW, Whincup PH, Emberson JR, Lampe FC, Walker M, Shaper AG. North-south gradients in Britain for stroke and CHD: are they explained by the same factors? Stroke. 2003;34:2604-9. 
9. Song YM, Ferrer RL, Cho SI, Sung J, Ebrahim S, Davey SG. Socioeconomic status and cardiovascular disease among men: the Korean national health service prospective cohort study. Am J Public Health. 2006;96:152-9.

10. Kuper $\mathrm{H}$, Adami HO, Theorell T, Weiderpass E. The socioeconomic gradient in the incidence of stroke: a prospective study in middle-aged women in Sweden. Stroke. 2007:38:27-33.

11. Robbins JM, Vaccarino V, Zhang H, Kasl SV. Socioeconomic status and type 2 diabetes in African American and non-Hispanic white women and men: evidence from the third National Health and nutrition examination survey. Am J Public Health. 2001;91:76-83.

12. Xu F, Yin XM, Zhang M, Leslie E, Ware R, Owen N. Family average income and body mass index above the healthy weight range among urban and rural residents in regional mainland China. Public Health Nutr. 2005;8(1):47-51.

13. Xu F, Yin XM, Zhang M, Leslie E, Ware R, Owen N. Family average income and diagnosed type 2 diabetes among urban and rural residents in regional mainland China. Diabet Med. 2006;23(11):1239-46.

14. Xu F, Yin XM, Zhang M, Leslie E, Ware R, Owen N. Cigarette smoking is negatively associated with family average income among urban and rural men in regional mainland China. Int J Ment Heal Addict. 2007;5(1):17-23.

15. National Bureau of Statistics of China. National Statistics of China 2016. Available from: http://www.stats.gov.cn/tjsj/ndsj/2016/indexch.htm. Accessed 20 Mar 2017.

16. Wang L, Hu Y, Lu Y, Su C. Analysis and comparison on 2000 and 2010 prevalence and risk factors of stroke in Suzhou. Chin Prim Health Care. 2013;27:76-8.

17. Gu L, Wang L, Zhu H, Wang J, Liu Y. The prevalence and risk factors of stroke among adults aged 35 years old or above in Xiaguan district of Nanjing. Chin J Clin Res. 2010;23:945-6.

18. Wang KA, Li TL, Xiang HD, Liu ZY, Bai J, Feng JG, Fu ZY, Ma LM, Chen JS, Jin SX, Li YQ, Qin RL, Chen H, Sun TJ, MAN QQ. Study on the epidemiological characteristics of diabetes mellitus and IGT in China. Chin J Epidemiol. 1998; 19(5):282-5.

19. Qu NN, Li KJ. Study on the reliability and validity of international physical activity questionnaire (Chinese vision, IPAQ). Chin J Epidemiol. 2004;25(3):265-8.

20. Wu ZS, Yao CH, Zhao D, Wu GX, Wang W, Liu J, Zeng ZH, Wu YK. SinoMONICA project: a collaborative study on trends and determinants in cardiovascular diseases in China, part I: morbidity and mortality monitoring. Circulation. 2001;103:462-8

21. Xu F, Yin XM, Tong SL. Association between excess bodyweight and intake of red meat and vegetables among urban and rural adult Chinese in Nanjing, China. Asia Pac J Public Health. 2007;19(3):3-9.

22. Xu LZ, Dibley MJ, D'Este C. Reliability and validity of a food-frequency questionnaire for Chinese postmenopausal women. Public Health Nutr. 2004;7:91-8.

23. Cooperative meta-analysis group of China obesity task force. Predictive values of body mass index and waist circumference to risk factors of related diseases in Chinese adult population. Chin J Epidemiol. 2002;23:5-8.

24. U.S. Department of Health and Human Services. 2008 Physical Activity Guidelines for Americans.Available at: http://www.health.gov/paguidelines. Accessed 20 Mar 2017

25. Marshall IJ, Wang Y, Crichton S, McKevitt C, Rudd AG, Wolfe CD. The effects of socioeconomic status on stroke risk and outcomes. Lancet Neurol. 2015 14(12):1206-18.

26. Feinstein JS. The relationship between socioeconomic status and health: a review of the literature. Milbank Q. 1993;71:279-322.

27. Kunst AE, Rios MD, Groenhof F, Mackenbach JP. Socioeconomic inequalities in stroke mortality among middle-aged men an international overview. Stroke. 1998;29:2285-91.

28. Lord S, Manlhiot C, Tyrrell PN, Dobbin S, Gibson D, Chahal N, Stearne K, Fisher A, McCrindle BW. Lower socioeconomic status, adiposity and negative health behaviours in youth: a cross-sectional observational study. BMJ Open. 2015;5(5):e008291.

29. Clarke PJ, O'Malley PM, Johnston LD, Schulenberg JE, Lantz P. Differential trends in weight-related health behaviors among American young adults by gender, race/ethnicity, and socioeconomic status: 1984-2006. Am J Public Health. 2009;99(10):1893-901.

30. Popkin BM. The nutrition transition and obesity in the developing world. J Nutr. 2001:131:871-3.

31. Florentino RF, Villavieja GM, Lana RD. Dietary and physical activity patterns of 8- to 10- year-old urban schoolchildren in Manila, Philippines. Food Nutr Bull. 2002;23:267-73.

32. Du SF, Lu B, Zhai FY, Popkin BM. A new stage of the nutrition transition in China. Public Health Nutr. 2002;5(1a):169-74
33. Popkin BM. Synthesis and implications: China's nutrition transition in the context of changes across other low- and middle-income countries. Obes Rev. 2014;15(Suppl 1):60-7.

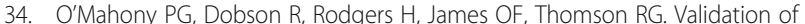
a population screening questionnaire to assess prevalence of stroke. Stroke. 1995;26:1334-7.

35. Wu GX, Wu ZS, He BL. Epidemiological characteristics of stroke in 16 provinces of China. Chin Med J. 1994;74:281-3.

36. Pfoertner T-K, Andress H-J, Janssen C. Income or living standard and health in Germany: different ways of measurement of relative poverty with regard to self-rated health. Int J Public Health. 2011:56(4):373-84.

37. Nanjing Municipal Bureau of Statistics. Local Consumer Price Index during 1979 and 2012. Available at: http://221.226.86.104/file/nj2004/2012/jiage/55.htm. Accessed on March 20, 2017. Accessed 21 Mar 2017.

\section{Submit your next manuscript to BioMed Central and we will help you at every step:}

- We accept pre-submission inquiries

- Our selector tool helps you to find the most relevant journal

- We provide round the clock customer support

- Convenient online submission

- Thorough peer review

- Inclusion in PubMed and all major indexing services

- Maximum visibility for your research

Submit your manuscript at www.biomedcentral.com/submit
) Biomed Central 